\author{
Barbara Steck \\ Felix Amsler \\ Andrea Grether \\ Alexandra Schwald Dillier \\ Christiane Baldus \\ Miriam Haagen \\ L. Diareme \\ John Tsiantis \\ Ludwig Kappos \\ Dieter Bürgin \\ Georg Romer
}

\section{Mental health problems in children of somatically ill parents, e.g. multiple sclerosis}

Accepted: 14 September 2006

Published online: 29 November 2006

B. Steck · F. Amsler · A. Grether

A.S. Dillier - D. Bürgin

Child and Adolescent Psychiatry

University of Basel

Schaffhauserrheinweg 55

4058 Basel, Switzerland

\section{Kappos}

Neurology Department

University of Basel

Universitätsspital, Petersgraben 4

4053 Basel, Switzerland

C. Baldus · M. Haagen · G. Romer Department of Child and Adolescent

Psychiatry and Psychotherapy

University Medical Centre

Hamburg-Eppendorf

Martinistr. 52

20246 Hamburg, Germany

L. Diareme $\cdot J$. Tsiantis

Department of Child Psychiatry

Athens University Medical School

"Adhia Sophia" Children's Hospital

Thivon and Levathias

EL-11527 Goudi, Greece

PD Dr. med. B. Steck ( $\square)$

Im Erlisacker 12

4103 Bottmingen, Switzerland

E-Mail: barbara.steck@unibas.ch
Abstract Objectives Based on the investigation of 144 families (144 patients affected by Multiple Sclerosis (MS), 109 partners, and 192 children) examined in three different European child and adolescent psychiatric University centres by means of questionnaires, we evaluated the prevalence of psychological symptoms in the offspring and associated risk factors such as duration and severity of the disease as well as depression of the ill and the healthy parent. Results Indicate that the severe disease of MS is associated with depression of the ill and healthy parent. Ill parents, especially ill mothers, as well as depressed ill, or depressed healthy parents evaluate their children's mental health problems with a higher prevalence within the internalizing spectrum. Healthy parents report normal psychological adjustment of their children. If two parents present a depressive state, the prevalence of relevant psychological internalizing symptoms is twice or three times as high as the age norms. Conclusion Children in families with a parent affected by MS and associated depression of the parental couple are at high risk of mental health problems, especially internalizing disorders. In focusing on the mental health of children one must also be aware of the potential opportunities to address the parents' own psychological needs.

Key words multiple sclerosis parental depression mental health problems in children

\section{Introduction}

Multiple Sclerosis (MS) confronts patients, partners, and their children with a wide array of challenges revolving around how to make sense of the disease experience and integrate it into their personal life.
MS is a complex disease where clinical manifestations and course vary considerably from one patient to another. It is now recognized, that despite its physical basis, psychiatric, and cognitive abnormalities are common in this disease and add considerably to the distress and disability of the patient 
(Brassington and Marsch 1998). The lifetime prevalence of depression in MS patients is estimated to be 47\%-54\% (Feinstein 2004; Minden 2000). These rates of depression are higher in MS patients than in the general population and among patients with general medical conditions (Minden et al. 1987). Changes in family roles, loss of work, income, or social status, and caregiver burnout are common in these families. Thus MS represents a disease condition that has the potential to affect the partner and children in a number of ways.

Somatic illness in a parent is a risk factor for psychiatric disorder in children (Romer et al. 2002; Rutter 1966). A significant physical disease in a parent has an impact on children's development and psychosocial functioning (Armsden and Lewis 1993; Steck et al. 2001; Worsham et al. 1997). The diagnosis of a severe somatic disease such as MS is one of the most life-changing events for patients, their families, and their children (Burnfield 1985; Kalb 1996; Steck 2000, 2002; White et al. 1996). In understanding the impact of the chronic somatic illness and in formulating interventions, it is helpful to consider, besides the developmental issues of the individual family member, also their interplay with the development of the family life cycle and the chronic illness itself (Rolland 1999).

This study investigated some risk factors of the outcome of psychological problems in families with a parent and children affected by MS on the basis of the following hypotheses:

\section{Parents associated hypothesis}

H1: Depression score is higher in ill parents than in healthy parents; there is mutual influence with respect to depressive symptoms between the parental couple.

H2: Disease variables such as duration and severity of MS are associated with depression in ill and healthy parents.

\section{Children associated hypothesis}

H3: Children of somatically ill parents will be at higher risk for psychological problems measured by symptom checklists than age norms; prevalent psychological symptoms in children exposed to parental MS will be found predominantly in the internalizing spectrum.

H4: Somatically ill parents tend to perceive more psychological problems in their children than healthy parents.
H5: The more severe the parental illness, the more the psychological symptoms found in his children.

H6: Low depression scores in ill and healthy parents will predict good psychological adjustment in their children.

\section{Country associated hypothesis}

H7: Gender and age of parents and offspring, disease variables, BDI, CBCL, and YSR values will show no major differences between countries.

\section{Statistics}

Differences between groups are compared with Chi square statistics (H4, H6, H7), t-tests (H1, H4), or one-way ANOVA with post hoc analysis including Bonferroni correction (H5, H6, H7).

Correlations between measures are calculated with Pearson correlation coefficients ( $\mathrm{H} 1, \mathrm{H} 2, \mathrm{H} 5, \mathrm{H} 6)$.

Comparison with norm values are calculated with Chi square statistics or one sample $t$-tests (H3).

\section{Subjects and methods}

\section{Participants}

The patients were recruited from the University hospitals of Hamburg (Germany; a special neurological outpatient service for patients with MS) of Athens (Greece; 5 neurological clinics, including the University) and of Basel (Switzerland; a specialized multidisciplinary team in the neurology department).

\section{Demographics}

Parents completed a self-report form to provide information on demographic variables such as age, gender, nationality of family members as well as educational levels, and work situation of both parents.

Illness status and illness severity was measured by the responsible physician, using the Karnofsky scale, an index for the clinical estimate of a patient's physical state, and performance. High percentage indicates minor symptoms, with the possibility of leading a normal life; low percentage indicates severe disease symptoms, or disability, with the necessity of institutional care.

Depression of the parents was assessed by the short form of the Beck Depression Inventory (BDI), which is a valid and reliable measure of depressive symptoms in both depressed and medical populations (Beck et al. 1961, 1988) and has been widely used in 
MS-patients, (e.g., Arnett et al. 2002; Feinstein and Feinstein 2001; Landro et al. 2004). "Somatic" BDI items might be valid as depression indicators for at least some MS patients (Aikens et al. 1997).

Child behavior checklist (CBCL, Achenbach 1991a) The CBCL is the best known of rating scale and checklist used to assess child mental health and behavior. It was used because of the ease with which it can be completed in population-based studies. Mother and father were both asked to complete the CBCL for each child, 6-18 years old. We evaluated these results separately and calculated the mean of both parent's rating as 'overall rating'.

The youth self report (YSR, with a setting identical to the CBCL) was completed by adolescents (age 11 or older); it provides a self-report measure of current behavioral and psychological status (Achenbach 1991b) and includes 102 items of the behavior problems from the CBCL, reworded in the first person.

According to national norms (Döpfner et al. 1994a, b; Roussos et al. 1999, 2001; Steinhausen et al. 1996, 1999) raw values of CBCL and YSR internalizing, externalizing, and total scores were transformed into standardized $T$-scores. To discriminate between relevant problems (need for diagnostic, counseling, or treatment) and non-relevant problems, we used the criteria $T \geq 60$ proposed by Achenbach (1991a, b) to define $C$ values, indicating cases with relevant problems. Around $17 \%$ of the children in the norm sample were rated as having relevant problems.

Possible sources of bias are different recruitment procedures (e.g., the questionnaires were mailed or handed over to the participants or filled out in an interview) and non-responders.

\section{Results}

\section{Demographic and clinical data (Table 1)}

Around $46 \%$ of the families are Swiss, $37 \%$ Greeks, and $17 \%$ Germans. Around $71.5 \%$ of the patients are female and $28.5 \%$ male. This reflects the fact that the ratio of women to men with MS is 3 to 2 . The gender distribution is similar among the three population samples. The distribution according to age and gender of the children is almost equal and does not differ between the three centres. Around $62.5 \%$ of the children are below, $37.5 \%$ above 12 years.

Mean score of the Karnofsky-Index is 70.9 and there are significant $(F=3.96 ; P=0.022)$ differences between the three countries: highest in Germany, followed by Greece and Switzerland. There are no gender differences.

Work situation (data not shown) of ill parents differs significantly $(P<0.001)$ between the three countries: there are more ill parents fully employed in Greece, whereas in Germany and Switzerland more ill parents are partly employed. Work situation of healthy parents does not show any significant difference. Highest education (data not shown) of ill and healthy parents does not differ significantly in the three centres (no differences between fathers or mothers and ill or healthy parents).

The BDI of ill parent and healthy parent differ significantly $(F=3.12 ; P=0.048)$ between the countries. The mean value of ill parents is 12.6 (corresponding to a mild depressive symptomatology) and differs significantly form the mean value of healthy parents $6.2(F=42.7 ; P<0.001)(\mathrm{H} 1) ; 59.5 \%$ of all ill parents $(68.6 \%$ of males and $56.0 \%$ of females) evaluate themselves as being depressed, whereas this is only true for $20.4 \%$ of the healthy parents $(13.6 \%$ of males and $31.2 \%$ of females). The correlations between duration of the disease (mean of duration for ill fathers is 6.5 years, for ill mothers 7.7 years) and severity of the illness are significant $(r=-0.33$; $P<0.01$ ), as well as between the severity of the disease and the depression of the ill parent $(r=-0.30$; $P<0.01)$. The longer the duration of and the more severe the disease, the more depressed is the ill parent. The more depressed the ill parent, the higher the depression score of the healthy parent $(r=0.23$; $P<0.05)(\mathrm{H} 2)$.
Table 1 Gender and age of patients, partners and children per country

\begin{tabular}{lllll}
\hline & Germany & Greece & Switzerland & Total \\
\hline Male patient $(N)$ & 5 & 15 & 21 & 41 \\
Female patient $(N)$ & 20 & 38 & 45 & 103 \\
Male offspring $(N)$ & 24 & 28 & 47 & 99 \\
Female offspring $(N)$ & 17 & 25 & 51 & 93 \\
Age of patient & $41.4( \pm 5.0)$ & $40.4( \pm 4.7)$ & $40.8( \pm 6.6)$ & $40.8( \pm 5.7)$ \\
Age of partner & $42.9( \pm 3.2)$ & $41.9( \pm 5.2)$ & $42.9( \pm 7.7)$ & $42.5( \pm 6.2)$ \\
Age of children & $10.5( \pm 3.3)$ & $10.3( \pm 3.9)$ & $9.3( \pm 4.8)$ & $9.8( \pm 4.8)$ \\
Karnofsky & $80.5( \pm 10.5)$ & $70.4( \pm 19.1)$ & $68.0( \pm 19.2)$ & $70.9( \pm 18.4)$ \\
BDI patient & $13.2( \pm 6.8)$ & $14.3( \pm 7.7)$ & $10.7( \pm 7.4)$ & $12.6( \pm 7.5)$ \\
BDI partner & $7.2( \pm 6.6)$ & $7.4( \pm 6.0)$ & $4.6( \pm 4.5)$ & $6.2( \pm 5.7)$ \\
\hline
\end{tabular}

Severity of disease and depression of patient and partner 
Table 2 CBCL and YSR T and C values overall (the mean of both parent's rating) evaluated by the ill, the healthy parent and the adolescent

\begin{tabular}{lllllll}
\hline & & $N$ & $T$ & Comparison norm $^{\text {a }}$ & C & Comparison norm $^{\text {b }}$ \\
\hline CBCL overall & Int & 154 & 52.3 & $* *$ & $21.4 \%$ & $t$ \\
& Ext & 154 & 51.2 & & $15.5 \%$ & \\
CBCL ill parent & Tot & 154 & 51.5 & & $16.9 \%$ & \multirow{2}{*}{. } \\
& Int & 148 & 52.4 & $*$ & $23.0 \%$ & $*$ \\
& Ext & 150 & 51.5 & $t$ & $18.7 \%$ & \\
CBCL healthy parent & Tot & 148 & 51.9 & $t$ & $21.6 \%$ & $t$ \\
& Int & 119 & 51.3 & & $21.0 \%$ & \\
YSR & Ext & 120 & 50.2 & & $15.0 \%$ & \\
& Tot & 119 & 50.5 & & $14.3 \%$ & \\
& Int & 66 & 53.2 & $* *$ & $23.9 \%$ & $t$ \\
& Ext & 66 & 51.8 & & $18.2 \%$ & \\
& Tot & 66 & 52.09 & $t$ & $18.2 \%$ & \\
\hline
\end{tabular}

Comparison with norm values

$t:{ }^{*} P<0.1 ;{ }^{* *} P<0.05 ;{ }^{* * *} P<0.01 ; P<0.001$

${ }^{a} T$ values are compared with 50 (norm)

${ }^{b} \mathrm{C}$ values are compared with $17 \%$

\section{Psychososocial problems (measured by CBCL/YSR) (Table 2)}

All overall CBCL $T$ and $C$ scores (the mean of both parent's rating) does not differ between countries with one exception: Swiss parents indicate a significantly $(8.1 \% ; P<0.01)$ smaller percentage of cases with relevant internalizing problems ( $C$ values) than Greek parents (29.4\%) and German parents (31.7\%).

CBCL $T$ overall externalizing and total scores do not differ significantly from the norm values of 50, whereas internalizing scores are significantly higher than norm values (H3). Ill parents rate their children's internalizing problems significantly higher than norm values, while healthy parents' ratings do not differ from the norm (H4).

\section{CBCL C scores}

Ill parents rate their children as having significantly relevant internalizing problems, whereas healthy parents' rating do not indicate an increased percentage of relevant problems (H4).

All YSR T and C scores do not differ significantly between countries.

YSR $T$ scores are significantly over the norm for internalizing disorders (H3). YSR C scores do not indicate an increased percentage of relevant problems.

To compare simultaneously the influence of father-mother and patient-healthy person, we calculated a two-way ANOVA and found an interaction effect between gender and illness for internalizing disorders $(F=5.7, P<0.05)$ and total score $(F=3.3$, $P<0.1)$ : ill mothers show the highest values in all three dimensions.

The correlations (Table 3 ) between the CBCL T values of the ill and the healthy parents for all dimensions are significant as well as between the
CBCL $\mathrm{T}$ values of the parents and the YSR T values of the adolescents for internalizing disorders. The correlations are higher between the YSR T values and the CBCL $T$ values, evaluated by the healthy parent, than the ones evaluated by the ill parent. Yet the differences between the correlation coefficients of the healthy parent and the ill parent with the adolescents do not achieve a significant level (Fishers $z$-values; data not shown).

The results of the correlations (Table 4) between the psychosocial problems (CBCL T values) evaluated by the ill and the healthy parent and different variables (gender, age, illness duration and severity, depression) show that only the severity of the disease and the depression of the parents are influencing the evaluation of the psychosocial problems in children. There is a significant inverse correlation between the Karnofsky Index and the CBCL $\mathrm{T}$ values (externalizing and total score). The more severely ill the parent is, the higher he or she evaluates the child as presenting psychosocial problems (H5). The correlations between the depression score of the ill mother, the somatically healthy parents (father and mother), and the CBCL T values are significant. The higher the depression score of the ill mother, the healthy father and the healthy mother, the higher their scoring for psychosocial problems in their children, particularly for internalizing symptoms, and for the total score (H6).

Table 3 Correlation between the psychosocial problems $(C B C L$, respectively YSR T values) evaluated by the ill parent, the healthy parent, and the adolescent

\begin{tabular}{lrllll}
\hline & $N$ & Internalizing & Externalizing & Total \\
\hline III parent-healthy parent & 113 & $r=0.64^{* * *}$ & $r=0.75^{* * *}$ & $r=0.73^{* * *}$ \\
III parent-adolescent & 56 & $r=0.48^{* * *}$ & $r=0.23$ & $r=0.25$ \\
Healthy parent-adolescent & 49 & $r=0.56^{* * *}$ & $r=0.46^{* * *}$ & $r=0.54^{* * *}$ \\
\hline
\end{tabular}

${ }^{*} P<0.05 ;{ }^{* *} P<0.01 ;{ }^{* *} P<0.001$ 
CBCL $T$ and $C$ scores of ill and healthy parents (Table 5) show a highly significant increase for internalizing disorders $(P<0.1-P<0.001)$ and total problems $(P<0.05-P<0.001)$ depending on the presence of none, one or two depressed parents. Especially the presence of two depressed parents increases the CBCL values remarkably.

YSR $C$ and $T$ scores (Table 5): $C$ scores for internalizing symptoms are almost three times, for total scores twice as high as the age norms in the presence of two depressed parents. They do not reach significant values, probably due to the small number.

\section{Discussion}

\section{Depression of parents}

Around $59 \%$ of all patients and $20 \%$ of the partners evaluate themselves as being depressed and the depression score is higher in ill parents than in healthy parents (confirming our first hypothesis).

\section{Depression of the ill parent}

Somatic disease and psychological disorders are closely interrelated (Verhaak 1997). According to Steele et al. (1997) increased illness severity predicted increased parental depressive symptoms. Numerous studies have identified elevated depressive symptom scores in MS patients, and studies of depressive disorders have clearly documented elevated prevalence rates in MS patients (Feinstein 2004; Minden 2000). The literature does not identify any specific pattern of neurological involvement as being consistently associated with depressive symptoms or disorders. Psychosocial risk factors contribute to the etiology of depression in MS, but the relative importance of various risk factors is not clearly determined. Biological, psychological, and social risk factors are all potentially important (Patten et al. 2000). Feinstein (2004) esti-

Table 4 Correlation between the psychosocial problems (CBCL T values) evaluated by the ill and the healthy parent and different variables (gender, age, illness duration and severity, depression)

\begin{tabular}{lclll}
\hline & $N$ & Internalizing & Externalizing & Total \\
\hline Gender of child & 154 & $r=0.08$ & $r=0.11$ & $r=0.09$ \\
Gender of patient & 154 & $r=0.12$ & $r=0.06$ & $r=0.14$ \\
Age of child & 154 & $r=0.11$ & $r=0.01$ & $r=0.05$ \\
Duration of illness & 152 & $r=-0.06$ & $r=-0.04$ & $r=-0.07$ \\
Karnofsky & 142 & $r=-0.14$ & $r=-0.18^{*}$ & $r=-0.19^{*}$ \\
BDI ill mother & 105 & $r=0.36^{* * *}$ & $r=0.15$ & $r=0.26^{* *}$ \\
BDI ill father & 44 & $r=0.29$ & $r=0.12$ & $r=0.24$ \\
BDI healthy mother & 41 & $r=0.35^{*}$ & $r=0.19$ & $r=0.41^{* *}$ \\
BDI healthy father & 78 & $r=0.36^{* *}$ & $r=0.23^{*}$ & $r=0.33^{* *}$ \\
\hline
\end{tabular}

* $P<0.05 ;$ ** $P<0.01$; ** $P<0.001$
Table 5 Influence of number of depressed parents on CBCL and YSR T and C values of somatically ill and healthy parents and adolescents

\begin{tabular}{|c|c|c|c|c|c|c|}
\hline & & & \multicolumn{3}{|c|}{$\begin{array}{l}\text { Number of } \\
\text { depressed parents }\end{array}$} & \multirow[t]{2}{*}{$P$} \\
\hline & & & 0 & 1 & 2 & \\
\hline \multirow[t]{6}{*}{ CBCL ill parent $(N=111)$} & Int & C & $6.7 \%$ & $22.6 \%$ & $38.9 \%$ & $* *$ \\
\hline & & $\mathrm{T}$ & 46.9 & 51.8 & 58.6 & $* *$ \\
\hline & Ext & C & $13.3 \%$ & $15.9 \%$ & $33.3 \%$ & \\
\hline & & $\mathrm{T}$ & 49.2 & 51.1 & 54.8 & \\
\hline & Tot & C & $13.3 \%$ & $22.6 \%$ & $38.9 \%$ & * \\
\hline & & T & 47.9 & 50.8 & 58.2 & * \\
\hline \multirow[t]{6}{*}{$\mathrm{CBCL}$ healthy parent $(N=110)$} & Int & C & $8.8 \%$ & $20.3 \%$ & $62.5 \%$ & $* * *$ \\
\hline & & $\mathrm{T}$ & 46.6 & 50.6 & 65.9 & **** \\
\hline & Ext & C & $14.7 \%$ & $10.0 \%$ & $31.3 \%$ & \\
\hline & & T & 49.4 & 49.5 & 55.5 & \\
\hline & Tot & C & $8.8 \%$ & $10.2 \%$ & $50.0 \%$ & $* *$ \\
\hline & & T & 47.8 & 49.2 & 62.6 & $* * *$ \\
\hline \multirow[t]{6}{*}{ YSR $(N=55)$} & Int & C & $25.0 \%$ & $20.7 \%$ & $50.0 \%$ & \\
\hline & & T & 49.7 & 53.8 & 57.4 & \\
\hline & Ext & C & $16.7 \%$ & 13.8 & $28.6 \%$ & \\
\hline & & $\mathrm{T}$ & 49.9 & 51.4 & 53.9 & \\
\hline & Tot & C & $16.7 \%$ & $17.2 \%$ & $38.5 \%$ & \\
\hline & & $\mathrm{T}$ & 49.9 & 52.5 & 54.2 & \\
\hline
\end{tabular}

$t: P<0.1 ;{ }^{*} P<0.05 ;{ }^{* *} P<0.01 ; * * * P<0.001$

Norm for $T$ values is 50 ; norm for $C$ values is $17 \%$

mates the lifetime prevalence of mayor depression to be approximately $50 \%$. Complaints such as irritability and sadness, hallmarks of affective instability, are often indicative of high levels of psychological distress. Given that depression and chronic medical conditions have unique and additive effects on patient functioning (Wells et al. 1989), it is of crucial importance to detect and treat depressive symptoms.

\section{Depression of the somatically healthy parent}

Psychological distress affects not only the chronically ill patient but also the caregiver (Aronson 1997). Caring is associated with experience of multiple losses (Cheung and Hocking 2004). Somatic, anxiety and depressive symptoms are common in these caring partners, and it is important for the professional healthcare team to recognize these symptoms and provide appropriate support (O'Brien 1993; Hakim et al. 2000; Knight et al. 1997).

\section{Depression, disease, and demographic variables}

Our results indicate that severe disease is associated with depression of ill and healthy parents (corresponding to the second hypothesis). The research on the potential associations between depression, physical disability and illness course in MS shows no consistent results (Minden and Schiffer 1990; Noy et al. 1995) According to a study by Mohr et al. (1997), depression (measured by the BDI) was sig- 
nificantly higher at more advanced levels of neurological impairment than at lower levels (measured by the Kurtzke EDSS). Chwastiak et al. (2002) studied the relationship of depressive symptoms and severity, duration and course of MS in over 700 patients and concluded that the severity of illness was more strongly associated with depressive symptoms than was the pattern of illness. Clinically significant depressive symptoms were present in $41.8 \%$ of the patients, and $29.1 \%$ of the subjects had moderate to severe depression. Kroencke et al. (2001) found that the level of heightened uncertainty (e.g., with exacerbations of MS) was associated with increase in depression. The results of Aikens et al. (1997) suggest that MS related depressive symptoms are a function of prior disease-related impairment and life stress. The incidence of pre-morbid depression or other psychiatric disturbances may be relevant. The way in which a person reacts to MS does not necessarily relate to the severity of the disease. A person who is only mildly affected can be psychologically distraught, while someone who is severally handicapped may cope very well. Many factors play a part in determining the individual's response (Brassington and Marsch 1998). These include the effect of disability on someone's normal way of life, previous strategies and patterns of coping and the extent of support received from others.

\section{Mental health problems in children}

\section{CBCL T/C and YSR T/C values compared to the norm values}

Both parents and offspring reported significantly higher scores for internalizing disorders only ( $T$ values), according to our third hypothesis. Our results show gender and role differences: especially ill mothers scored high for psychological problems in their children, particularly for internalizing disorders. There are no discrepancies between the evaluations of ill and healthy parents, neither between the evaluation of ill or healthy parents and their children ( $T$ values). The differences between ill and healthy parents in their evaluation of their children having "relevant problems" ( $C$ values) are interesting. For ill parents their children present relevant internalizing psychological problems, healthy parents and adolescents indicate no relevant problems. These results confirm our fourth hypothesis. The more severely ill the parent is, the higher he or she evaluates the child as presenting psychosocial problems (corresponding to our fifth hypothesis).

Ill and healthy parents perceive their children differently. Ill parents-who experience high anxiety with their disease-may not accurately assess their children's true emotional state. Healthy parents-on the contrary-may have a tendency to ignore problems, therefore evaluating their children too positive. Youth may minimize their emotional difficulties or mask their true emotions to protect their parents. Parents often have difficulties in acknowledging the effect of the illness on children (Levine and Krieger 1993). The parental need to believe that children are not affected by their own MS prevents them from seeking help (Kalb 1996). False perceptions could possibly prevent children and adolescents from receiving appropriate mental health interventions (Heiney et al. 1997).

Especially ill mothers evaluate their children as presenting internalizing disorders. The results of Najman et al. (2001) show that the more emotionally disturbed the mother, the greater the degree to which she imputes the child to have behavioral problems (measured by the CBCL/YSR); the data suggest-according to the authors-that maternal health impairment is associated with biased observations.

\section{Psychosocial problems (CBCL T values) and parental depression (measured by the BDI)}

The higher the depression score especially of ill mothers and even more of healthy parents, the higher the psychosocial problems are evaluated in their children, particularly for internalizing symptoms and for the total score. The depression of both parents predicts twice to three times a higher percentage of relevant internalizing problems in their children and adolescents. These findings confirm our sixth hypothesis. The high potential risk for mental health disorders in offspring of a depressed parental couple indicates strongly the main target of preventive interventions. Steele et al. (1997) in his studies shows that parental illness impacts child internalizing symptoms by operation through parental depressive symptoms. There is ample evidence for the association between parental mental disorders and children's adjustment (Beardslee et al. 1998; Davies and Windle 1997; Olfson et al. 2003) and between the adverse effect of maternal depression on children's psychological health (Brennan et al. 2000, 2003). Our findings confirm previous studies, where the depression of parents affected by MS, followed by single parenthood, represented the most unfavorable context for the development of children's psychopathology (Steck et al. 2005). Fergusson et al. (1993) calculated that maternal depression had a causal influence, explaining about $7 \%$ of the error variance in maternal reports. They concluded that use of maternal reports to measure 
child behavior could result in serious overestimation of correlations between maternal depression and child behavior. Depressed mothers reported a three time greater risk of serious emotional problems in their children compared to non-psychiatric controls (Weissman et al. 2004). The results of a longitudinal study (Anderson and Hammen 1993), suggest that the psychosocial problems (measured by the CBCL) observed in children of mothers with recurrent depressions are long-lasting and are apparent in their functioning both at home and at school (CBCL for teachers).

Numerous studies indicate that the quality of the emotional availability of the healthy parent may compensate for the inattentiveness of the ill parent. The child's significant relationship with the healthy non-depressed parent may be a key protective factor for his psychological adjustment (Davies and Windle 1997; Leinonen et al. 2003).

\section{Differences between countries}

The investigated sample size of patients, partner, and children was highest in Switzerland, followed by Greece and Germany. This raises the question whether these differences in cohort size introduce a bias. Disease severity varies significantly between the three countries, which might be explained by differences in referral patterns. The mean values of depression of ill and healthy parents differ significantly between the three countries, being lowest in Switzerland. Therefore it is not surprising that Swiss parents evaluate their children (CBCL C values) at $92 \%$ within the norm (i.e., presenting no internalizing disorders, in comparison to the significant lower percentage by Greek and German parents. Socioculturally mediated factors may influence differences in illness behavior and defense mechanism. Parents affected by MS and their family fear stigmatization through their physical disability. Some parents even wish-as long as possible-to keep their disease secret and therefore do not acknowledge associated depressive symptoms. They underestimate the emotional distress of their children, since any psychological or mental health problem would mean further stigmatization (Steck et al. 2005). Another source of bias may be the different handling of questionnaires: they were mailed, handed over to the participants, or filled out in an interview.

\section{Conclusions}

Ill and healthy parents with depression and particularly the depressed parental couple overestimate the potential risk of mental health problems, especially internalizing symptoms, in their children. Healthy parents and partially also adolescents underestimate this risk. Comprehensive care of the person with MS involves the entire family. When the parent with MS is evaluated, the healthy parent should be included. The careful assessment of disease variables in ill and healthy parents is needed to devise individualized treatment approaches to manage problems that might arise in both, for example depression. The importance of the healthy parent's mental health and emotional availability for the children has to be emphasized. The results suggest a number of interventions, which may reduce the negative effects of parental MS on a child. Specifically interventions aimed at helping parents to cope with the illness situation and to decrease individual parental depressive symptoms (Landoni et al. 2000; Leahey and Wright 1985; Minden 1992; Padrone 1994; Steinglass 1992) may work to help children with their psychosocial adjustment. According to Beardlsee et al. (1993), a preventive intervention is meaningful for children whose parents are depressed. For White (1998), to treat the family with a parent affected by MS is to provide the patient with essential care. One does not need to treat all aspects of the family to show fundamental improvement in the system. If the healthy parent attends a support group, his or her ability to care for the patient may increase what could reduce his or her own depression.

Despite a number of strengths of this study, it is not without its limitations. Our results must be considered cautiously, given the heterogeneous nature of the sample, e.g., the implications of the parental disease, the time since onset and diagnosis and the varying duration of exposure of children to the parental illness. Other limitations are associated with this investigation, and the findings should therefore be evaluated with appropriate prudence. Neuropsychological investigation has not been conducted, so the influence of cognitive disorders on associated depression in ill and healthy parents was not evaluated, neither the psychosocial impact of cognitive impairment on family and especially children. Children's concern and emotional distress are more strongly associated with less apparent psychological changes such as cognitive dysfunction or depression than with the more visible, physical symptoms, e.g., ambulation (Kalb 1996). Longitudinal research is needed to understand clearly the interactions between normal developmental variations and the variations produced by the presence of a chronic physical illness of parents children and adolescents. One cannot exclude the eventual bias in the data collection by three different teams. 
Acknowledgement This study is part of an international multisite research project, which was supported by a grant from the European Union in its 5th Framework Program. "Quality of Life" (QLGT-2001-02378): "Mental Health Prevention in a Target Group at Risk: Children of Somatically Ill Parents (COSIP)". The following institutions and Principal Investigators collaborated in this project: (1) Dept. of Child and Adolescent Psychiatry and Psychotherapy, University Hospital Hamburg-Eppendorf, Germany (Dr. med. Georg Romer); (2) Dept. of Child and Adolescent Neuropsychiatry, University of Vienna, Austria (Prof. Dr. med. M. Friedrich); (3) Department of Psychology, University of Aarhus, Denmark (M.
Thastum, Ph. D.); (4) Child Psychiatry Clinic, Turku University Hospital, Finland (Prof. Dr. J. Piha); (5) Department of Child Psychiatry, Athens University Medical School, Greece (Prof. Dr. J. Tsiantis); (6) Clinic of Child and Adolescent Psychiatry, University of Medicine and Pharmacy, Bucharest, Romania (Prof. Dr. S. Milea); (7) Clinic of Child and Adolescent Psychiatry, University of Basel, Switzerland (PD Dr. B. Steck); (8) Department of Psychological Medicine, Royal Marsden Hospital, Sutton, United Kingdom (M. Watson, Ph. D.). This study was also supported by the Swiss Multiple Sclerosis Society.

\section{References}

1. Achenbach T (1991a) Manual for the child behaviour checklist and 1991 profile. University of Vermont, Department of Psychiatry, Burlington

2. Achenbach T (1991b) Manual of the youth self report and 1991 profile. University of Vermont, Department of Psychiatry, Burlington

3. Aikens JE, Fischer JS, Namey M, Rudick, RA (1997) A replicated prospective investigation of life stress, coping, and depressive symptoms in multiple sclerosis. J Behav Med 20(5):433-445

4. Anderson CA, Hammen CL (1993) Psychosocial outcomes of children of unipolar depressed, bipolar, medically ill and normal women: a longitudinal study. J Consult Clin Psychol 61(3):448-454

5. Armsden G, Lewis FM (1993) The child's adaptation to parental medical illness: Theory and clinical implications. Patient Education and Counseling 22(3):153-165

6. Arnett PA, Higginson CI, Voss WD, Randolph JJ, Grandey AA (2002) Relationship between coping, cognitive dysfunction and depression in multiple sclerosis. Clin Neuropsychol 16(3):341-355

7. Aronson KJ (1997) Quality of life among persons with multiple sclerosis and their caregivers. Neurology 48:7480

8. Beardslee WR, Salt P, Portefield K, et al. (1993) Comparison of preventive interventions for families with parental affective disorder. J Am Acad Adolesc Psychiatry 32:254-263

9. Beardslee WR, Versage EM, Gladstone TRG (1998) Children of affectively ill parents. A review of the past 10 years. J Am Acad Child Adolesc Psychiatry 37:1134-1141

10. Beck AT, Steer RA, Garbin MG (1988) Psychometric properties of the Beck Depression Inventory: twenty-five years of evaluation. Clin Psychol Rev 8:77-100
11. Beck AT, Ward C, Mendelson M, Mock J, Erbaugh, J (1961) An inventory for measuring depression. Arch Gen Psychiatry 4:53-63

12. Brassington JC, Marsh NV (1998): Neuropsychological aspects of multiple sclerosis. Neuropsychol Rev 8(29):4377

13. Brennan PA, Hammen C, Andersen MJ, Bor W, Najman JM, Williams GM (2000) Chronicity, severity and timing of maternal depressive symptoms: relationship with child outcomes at age 5. Dev Psychopathol 36:759-766

14. Brennan PA, Broque RL, Hammen C (2003) Maternal depression, parentchild relationship, and resilient outcomes in adolescence. J Am Acad Child Adolesc Psychiatry 42:1469-1477

15. Burnfield A (1985) Multiple sklerose: a personal exploration. Souvenir Press Ltd, London

16. Cheung J, Hocking, P (2004) The experience of spousal carers of people with multiple sclerosis. Qual Health Res 14(2):153-166

17. Chwastiak L, Ehde DM, Gibbons LE, Sullivan M, Bowen JD, Kraft, GH (2002) Depression symptoms and severity of illness in multiple sclerosis: epidemiologic study of a large community sample. Am J Psychiatry 159:1862-1868

18. Davies PT, Windle, M (1997) Genderspecific pathways between maternal depressive symptoms, family discord, and adolescent adjustment. Dev Psychol 33:657-668

19. Döpfner M Schmeck K, Berner W (1994a) Handbuch: Elternfragebogen über das Verhalten von Kindern und Jugendlichen, Forschungsergebnisse zur deutschen Fassung der Child Behaviour Checklist (CBCL), 1.Auflage, KJFD, Arbeitsgruppe Kinder-, Jugendund familiendiagnostik. Köln

20. Döpfner M Schmeck K, Lehmkuhl G (1994b) Handbuch: Fragebogen für Jugendliche, Forschungsergebnisse zur deutschen Fassung des Youth Self Re- port (YSR) der Child Behaviour Checklist (CBCL), 1.Auflage, KJFD, Arbeitsgruppe Kinder-, Jugend-und familiendiagnostik. Köln

21. Feinstein A, Feinstein K (2001) Depression associated with multiple sclerosis looking beyond diagnosis to symptom expression. J Affect Disord 66:193-198

22. Feinstein A (2004) The neuropsychiatry of multiple sclerosis. Can J Psychiatry 49(3):157-163

23. Fergusson DM, Lynskey MT, Horwood LJ (1993) The effect of maternal depression on maternal ratings of child behaviour. J Abnorm Child Psychol 21:245-269

24. Hakim EA, Bakheit AM, Bryant TM, Roberts MW, McIntosh-Michaelis SA, Spackman AJ, Martin JP, McLellan DL (2000) The social impact of multiple sclerosis: a study of 305 patients and their relatives. Disabil Rehabil 22(6):288-293

25. Heiney SP, Bryant LH, Walker S, Parrish RS, Provenzano FJ, Kelly KE (1997) Impact of parental anxiety on child emotional adjustment when a parent has cancer. Oncol Nurs Forum 24(4):655-661

26. Kalb RC (1996) The impact of multiple sclerosis on the family. Int MSJ 3(2):65-69

27. Knight RG, Devereux RC, Godfrey HPD (1997) Psychosocial consequences of caring for a spouse with multiple sclerosis. J Clin Exp Neuropsychol 19(1):7-19

28. Kroencke DG, Denney DR, Lynch SG (2001) Depression during exacerbations in multiple sclerosis: the importance of uncertainty. Mult Scler 7:237242

29. Landoni MG, Giordano MT, Guidetti GP (2000) Group psychotherapy experiences for people with multiple sclerosis and psychological support for families. J Neurovirol 6 (Suppl 2):S168S171 
30. Landrø NI, Gulowsen Celius E, Sletvold H (2004) Depressive symptoms account for deficient information processing speed but not for impaired working memory in early phase multiple sclerosis (MS). J Neurol Sci 217:211-216

31. Leahey M, Wright L (1985) Intervening with families with chronic illness. Fam Syst Med 3(1):60-69

32. Leinonen JA, Solantaus TS, Punamaki RL (2003) Parental mental health and children's adjustment: the quality of marital interaction and parenting as mediating factors. J Child Psychol Psychiatry Allied Disciplines 44(2):227-241

33. Levine HB, Krieger JG (1993) Adjustment of adult children of parents with MS. Institute for Health Policy, Massachusetts

34. Minden SL, Orav J, Reich P (1987) Depression in multiple sclerosis. Gen Hosp Psychiatry 9:93-97

35. Minden SL, Schiffer RB (1990) Affective disorders in multiple sclerosis. Review and recommendations for clinical research. Arch Neurol 47(1):98-104

36. Minden SL (1992) Psychotherapy for people with multiple sclerosis. J Neuropsychiatry Clin Neurosci 4(2):198213

37. Minden SL (2000) Mood disorders in multiple sclerosis: diagnosis and treatment. J Neurovirol 6(Suppl 2):S160-S167

38. Mohr DC, Goodkin DE, Gatto N, Wende JVd (1997) Depression, coping and level of neurological impairment in multiple sclerosis. Mult Scler 3(4):254-258

39. Najman JM, Williams GM, Nikles J, Spence S, Bor W, O'Callaghan R, Le Broque R, Andersen MJ, Schuttlewood GJ (2001) Bias influencing maternal reports of child behaviour and emotional state. Soc Psychiatry Psychiatr Epidemiol 36:186-194

40. Noy S, Achiron A, Gabbay U, Barak Y, Rotstein Z, Laor N, Sarova-Pinhas I (1995) A new approach to affective symptoms in relapsing-remitting multiple sclerosis. Compr Psychiatry 36(5):390-395
41. O’Brien MT (1993) Multiple sclerosis: stressors and coping strategies in spousal caregivers. J Community Nurs 10:123-135

42. Olfson M, Marcus SC, Druss B, Pincus HA, Weissmann MM (2003) Parental depression, child mental health problems, and health care utilization. Med Care 41(6):716-721

43. Padrone FJ (1994) Psychotherapeutic issues with family members of persons with physical disabilities. Am J Psychiatry 48(2):195-207

44. Patten SB, Metz LM, Reimer MA (2000) Biopsychosocial correlates of lifetime major depression in a multiple sclerosis population. Mult Scler 6:115-120

45. Rolland JS (1999) Parental illness and disability: a family systems framework. J Fam Ther 21:242-266

46. Romer G, Barkmann C, Schulte-Markwort $M$, Thomalla $G$, Riedesser $P$ (2002) Children of somatically ill parents: a methodologic review. Clin Child Psychol Psychiatry 7(1):17-38

47. Roussos A, Karantanos G, Richardson C, Hartmann C, Karajiannis D, Kypranos S, Lazaratou $\mathrm{H}$, Maihaira $\mathrm{O}$, Tassi M, Zoubou V (1999) Achenbach's child behaviour checklist and teacher's report form in a normative sample of greek children. Eur Child Adolesc Psychiatry 8(3):165-172

48. Roussos A, Francis K, Zoubou V, Kiprianos S, Prokopiou A (2001) The standardization of Achenbach's youth self-report in Greece in a national sample of high school students. Eur Child Adolesc Psychiatry 10:47-53

49. Rutter M (1966) Children of sick parents. An environmental and psychiatric study. Oxford University Press, London

50. Steck B (2000) The psychosocial impact of multiple sclerosis on families and children. Int MS J 7(2):63-70

51. Steck B (2002) Multiple Sklerose und Familie, Psychosoziale Situation und Krankheitsverarbeitung. Karger Verlag, Basel

52. Steck B, Amsler F, Dillier AS, Grether A, Kappos L, Bürgin D (2005) Indication for psychotherapy in offspring of a parent affected by a chronic somatic diseas (e.g. multiple sclerosis). Psychopathology 38:38-48
53. Steck B, Amsler F, Kappos L, Bürgin D (2001) Gender-specific differences in the process of coping in families with a parent affected by a chronic somatic disease (e.g. multiple sclerosis). J Psychopathol 34:236-244

54. Steele RG, Forehand R, Armistead L (1997) The role of family processes and coping strategies in the relationship between parental chronic illness and childhood internalizing problems.Jof abnorm. Child Psychol 25(2):83-94

55. Steinhausen H-C, Metzke CW, Kannenberg R (1996) Elternfragebogen über das Verhalten von Kindern und Jugendlichen. Zürich: Psychiatrische Universitäts-Poliklinik für Kind

56. Steinhausen H-C, Metzke CW, Kannenberg R (1999) Fragebogen für Jugendliche. Zürich: Psychiatrische Universitäts-Poliklinik für Kind

57. Steinglass P (1992) Multifamily group therapy, multiple sclerosis and the family. Demos Publications, New York pp 83-96

58. Verhaak PF (1997) Somatic disease and psychological disorder. J Psychosom Res 42(3):261-273

59. Weissman MM, Feder A, Pilowsky DJ, Olfson M, Fuentes M, Blanco C, Lantigua R, Gameroff MJ, Shea S (2004) Depressed mothers coming to primary care: maternal reports of problems with their children. J Affectice Disord 78:93-100

60. Wells KB, Stewart A, Hays RD, Burnam MA, Rogers W, Daniels M, Berry S, Greenfield S, Ware J (1989) The functioning and well-being of depressed patients. Results from the medical outcomes study. JAMA 262:914-919

61. White DM, Catanzaro RN, Buchholz A (1996) Psychological issues among adolescents in families in which a parent has multiple sclerosis. Report to the National Multiple Sclerosis Society, New York

62. White DM (1998) Treating the family with multiple sclerosis. Phys Med Rehabil Clin N Am 9(3):675-687

63. Worsham N, Compas B, Sydney E (1997) Children's coping with parental illness. In: Sandler W (ed) Handbook of children's coping: linking theory and intervention. New York, pp 195213 